\title{
Earthquake Risk and Insurance - Policy Considerations: The Israeli Case
}

\author{
by Yehuda Kahane*
}

\section{The earthquake risk and its management}

Earthquake is considered to be among the most destructive powers in nature. Although in the long run, the economic losses and the death toll caused by floods, storms and other disasters are higher than those caused by earthquakes, the destructive potential of a single earthquake is tremendous, and the damage may spread over large areas. The energy released from an earthquake of magnitude 8 on the Richter scale resembles that of an explosion of approximately 100 megatons of TNT. Such a quake will be felt over areas hundreds of kilometers from its epicenter, and the losses to a large city hit by an earthquake of this magnitude could be in the range of thousands of lives and billions of dollars (see Gere et al. [1984] and Roth et al. [1986]). Such losses could form a considerable percentage of the annual GNP of a small country.

Some areas are more vulnerable than others: certain areas have higher probability of being hit, or higher loss potential due to the specific subsoil conditions, the concentration of industries or population, the construction methods used, etc. The loss of lives depends on these factors and also on the timing of the quake.

It is only natural that a fear of earthquake bothers the public, landlords, government and insurers. The insurance problems are serious, due to the catastrophic nature of the risk (high positive correlation between the individual exposures). There are also additional problems related to the uncertainty, which make the setting of premiums and reserves difficult, and the availability of reinsurance coverage unsure.

1.1 Earthquake - what is it? It is assumed that earthquakes are connected to the structure of the earth's surface, which is made up of huge rigid plates in continuous motion. Maps have been drawn up showing that earthquakes and volcanic activities are

* Academic Director, The Erhard Insurance Center, Faculty of Management, Graduate School of Business, Tel Aviv University, Ramat Aviv, Israel.

The author is a member of the Israeli national committee on earthquake insurance. The views expressed in this paper do not necessarily reflect those of the other members of the committee, or of any official policy on the subject, nor do they necessarily represent those of the institutions with which he is affiliated.

I would like to thank Mr. E. Arieh, who introduced me to the interesting world of seismology and provided helpful comments on this paper. I wish to thank also the Munich-Re Corporation and especially Dr. Berz for sending me their comprehensive publications on the topic, with additional comments and suggestions. All remaining errors in the paper are my responsibility. 
concentrated along the seams between the plates (some of them being in the middle of oceans) and this is explained by the stresses, tensions and friction created by the movements of these plates. When energy is released suddenly the result is an earthquake. Earthquakes occur at various depths under the earth's surface - some of them at a depth of a few hundred kilometers, but most of them closer to the surface. Those earthquakes which occur close to the surface (say, to a depth of 5-25 km) are considered the more dangerous and most frequent ones. Though the shock of deep earthquakes is absorbed for the most part before they reach the surface (see ROA [1986] p. 4) some destructive earthquakes have occurred at greater depths.

The world's main seismic activity is concentrated in the so-called Circumpacific Belt, where some $80 \%$ of the total world seismic energy is released. (The recent disasters in Mexico and El Salvador are expressions of this activity - which is created by the largest and fastest moving Pacific Plate.) Another $15 \%$ of the energy is released in the strip between Asia and Europe (the Alpide belt which passes through Greece and Turkey). All other areas, including the Middle East, are less active, releasing altogether less than $5 \%$ the of world's energy (see Gommitz [1974], ROA [1986]).

A number of studies (e.g., Shpilberg and Pinedo [1979], Boissonnade and Shah [1985] suggest that there may be some connection between time that has elapsed since a previous earthquake and the probability of a strong earthquake occurring. This may be the result of the accumulation of potential energy, ready to released. In other words, the statistical process describing earthquake occurrence is not lacking in "memory". It is now believed that the risk of a severe earthquake is greater in areas with an exceptionally long seismic gap.

1.2. The measurement of earthquake strength: There are number of methods used to measure and rank earthquake strength, two of which are more popular than the rest: the Richter scale measures the magnitude of the earthquake, and reflects the energy released at the surface. The (modified) Mercalli scale measures the intensity (i.e., the effect of the earthquake on structures and surfaces at various distances and locations away from the source).

Richter Scale: This scale can be related to the energy released, and is based on a logarithmic scale. Moving one point along the scale expresses a multiplication of the energy by a factor of approximately 30 . The maximum earthquake measure has a magnitude 9.2 on the Richter scale. The magnitude of an earthquake is evaluated from instrumental measurements and corrected for the distance to the source $\left(M_{L}\right)$. A somewhat similar measure based on the surface wave magnitude - is denoted by $M_{S}$.

The magnitude of the earthquake does not relate directly to its observed effects. This is so since two similar energy releases could be spread over different areas. The effects are related to the earthquake's magnitude, the subsoil conditions and its attenuation properties, the structures, the building materials and to other parameters.

Mercalli Scale: Other scales measure the intensity of the quake from its observed effects on the surface. Such scales are more useful for insurance-related problems. The Modified Mercalli scale (MM), in use today in the U.S. and other countries, was introduced at beginning of the century and modified in the 1950's. It has 12 levels, marked in Roman numerals according to subjective evaluation of the effects felt on the surface (see 
Appendix 1). The correlation between the intensity and ground acceleration is poor. Howerer, insurers often refer to such relationships - stating that a strong earthquake (intensity VII) is possibly accompanied by accelerations in the range of $0.05-0.1 \mathrm{~g}$ (see Munich- $\mathrm{Re}$ [1982]), while at an intensity of XII the acceleration could reach $2 \mathrm{~g}$ and may even exceed this level! (The effect of vertical acceleration of $1 \mathrm{~g}$ is equivalent to the effect of dropping a building from 10 meters!)

Due to different geological conditions (attenuation factors), an earthquake of a given magnitude could create different effects (intensities) in other zones, which might be felt over different areas.

1.3. The frequency and severity of earthquakes: Seismic measurements are a relatively new phenomenon. The use of the Mercalli scale enables the evaluation of the intensity of recorded past occurrences even in the absence of seismographs, and these pieces of information are gathered to give a rough estimate of the magnitude. Such studies reflect, of course, the population density and its culture (written records) more than the earthquake itself. Even when records are available, they are often incomplete or inaccurate, especially concerning the specific dates. Therefore it is not always clear whether all quakes have been reported, and whether the records relate to different occurrences or rather to one event with inaccurately reported dates, and its possible after shocks. Changes in population centers limit the validity of some of the studies. Moreover, construction methods have changed, and an earthquake which would have destroyed primitive buildings will leave modern ones unaffected, and vice versa - an earthquakes which affected only a small area in the past could be destructive over a much greater distance, due to the sensitivity of high-rises to distant earthquake (resonance effect).

The analysis of earthquake frequencies is done using statistical methods, and is typically based on fitting certain distribution functions (e.g., Normal, Log-Normal, Poisson see Gomitz [1974], Shpilberg and Pinedo, [1977], Johnston and Nava [1984] and Boissonade and Shah [1985]). Such studies unfortunately, typically give too wide confidence intervals, and this limits their applicability.

The earthquake risk is a combination of two stochastic variables: frequency and severity. It should, therefore, be analyzed using compounded distributions. Certain approximations like those presented below could be made in order to obtain a rough idea of the expected loss.

1.4. The physical effects of earthquakes. (ROA [1986] pp. 7-19): Most of the direct earthquake losses (property damage, as well as loss of lives) and some of the indirect losses (business interruption) result from the failure of man-made structures. Therefore, this article focuses mainly on the effects of earthquakes on buildings and other structures.

The seismic hazard depends on factors such as the magnitude of the earthquake at the epicenter and the amount of energy released, the depth of the epicenter ("focal depth"), the duration of the quake, the amplitude and frequency of the vibrations, the type of rock through which the seismic wave passes from the epicenter to the affected area and its attenuation. The seismic risk is affected by factors such as the dynamic features of the buildings and their foundations, the specific exposures of the area, type and density of structures 
(housing, industry, transportation systems, public structures, etc.), the importance of the buildings, their values, the type and value of the contents, the importance of continuing service, etc. Earthquakes often occur as a series of shocks and aftershocks (which may occur a few hours, days, or even a few weeks later). They have the following effects:

1) Ground movements: Earthquakes occur along geological faults and create vertical and horizontal movements and tectonic deformations.

2) Vibrations: Earthquakes are characterized by vibrations which are transfered to the structures. The tremor vibrates the building in a certain pattern, which generates stresses of varying intensities and in many directions, which puts to test the dynamic balance of the building. The damage due to vibrations depends on a large number of parameters.

It is believed that damage to buildings is determined by the type of rock, the foundations and the quality of the constructions. Certain structures are affected by shorter vibrations while others are affected more by durable vibrations. This is related to the resonance, the balance of the structure, and its size. For example, large restaurants, lobbies and stores on the ground floor of hotels make this floor "soft", while the top floors are heavy. The force of the earthquake is concentrated on the ground floor and the other floors operate as a pendulum. Poor design could end up with the collapse of the entire structure.

Tall structures react badly to long waves. As a rule of thumb: the resonance frequency of high-rise buildings corresponds to the number of floors divided by 10 . A 10-storey building, for example, will be severely affected by an earthquake with a cycle of 1 second. The accuracy of this rule depends on the type of structure and subsoil conditions: flexible buildings have a larger resonance period.

The crust absorbs the short waves and lets long ones pass. Therefore, tall buildings may still be affected even though they are located at a geat distance from the epicenter (they "smell" the earthquake). The damage depends also on the duration of the quake and the distance from the epicenter. Long earthquakes give enough time for the amplitude of the oscillations of high-rises to reach its peak. Due to these effects a near and short quake will affect mostly the low buildings. A longer tremor will affect both low and tall buildings. A distant quake, with longer duration will afffect mainly the high-rise buildings. The type of foundation dictates to a large extent the permissible height of the building.

Horizontal vibrations and acceleration are extremely damaging to buildings, especially tall ones, due to shearing effects, and engineers expend much effort in designing more balanced and ductile buildings to better withstand such movements. In addition, maintain ing a balanced allocation of weight, symmetric shape and keeping an appropriate distance between neighboring buildings help to mitigate earthquake losses.

Strong earthquakes are often followed by powerful aftershocks, which may have disastrous effects, especially on structures already weakened by the first tremor (Munich-Re, Managua report [1972]). A repeated tremor even of weaker magnitude could be devas tating.

3) Changes of the land surface: Earthquakes can result in landslides, settlement (thereby destroying ports, making buildings lean over to one side, etc.) or liquifaction of the soil, making the foundations of buildings unstable, and causing collapse or damage to structures.

4) Secondary effects: Earthquakes may produce waves at sea (tsunamis) which are created when a huge mass of water is suddenly shifted. A tsunami may advance at great speed 


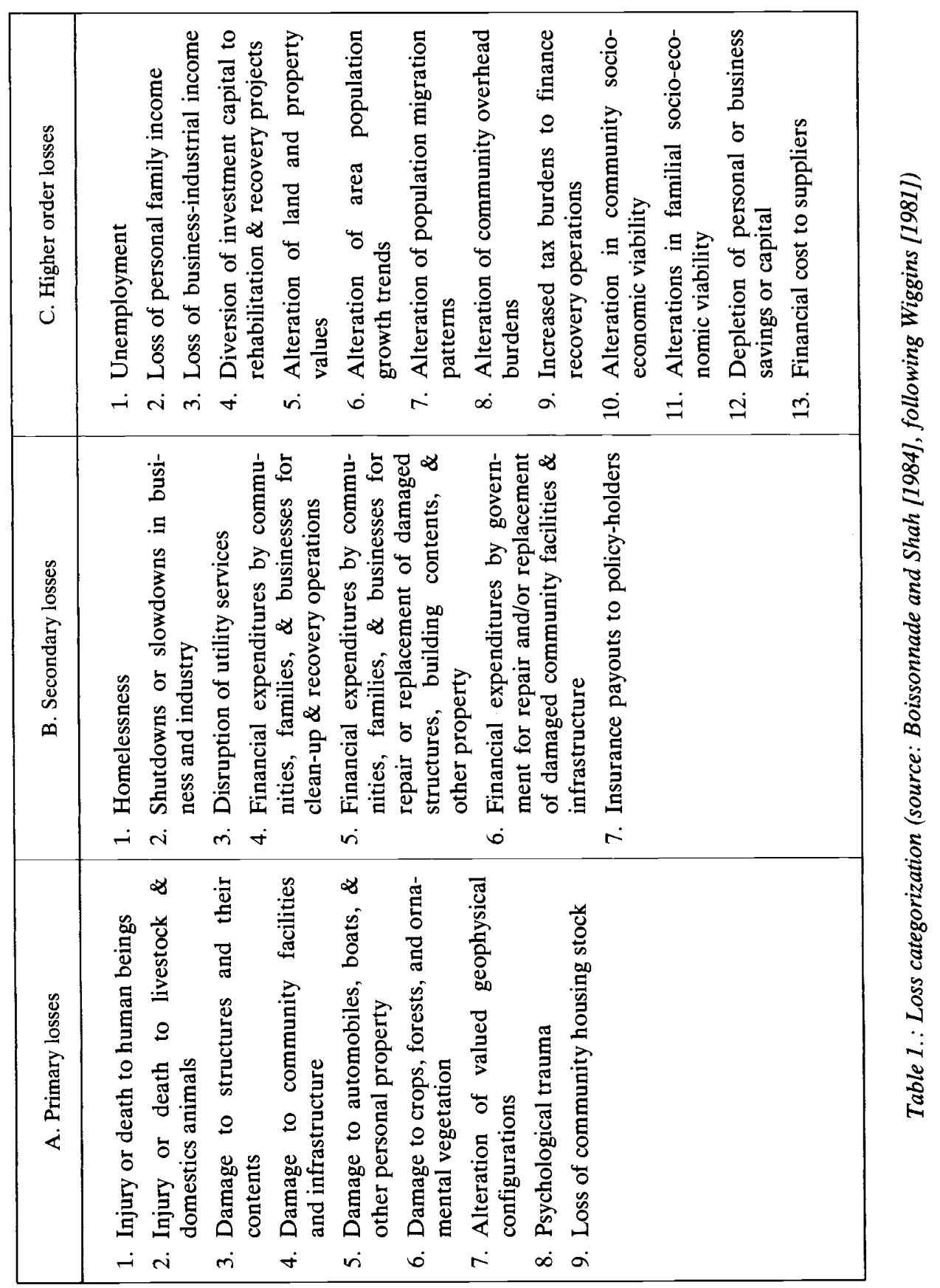


(up to $500 \mathrm{mph}$ !). The wave is observed only near the coast, where it can suddenly reach a siginificant height (heights of some thirty meters have been recorded in Japan and Hawaii, and of a few meters in the Mediterranean). The effects of tsunamis can be disastrous, especially in narrow bays and along flat coastlines. The wave spreads in all directions and its speed is higher when it develops in deep water. The damage depends on the coastal topography, and the exposures in the area (concentration of values like hotels or industries). Tsunamis have been reported to cause the death of thousands of people, and to destroy boats and ships and thousands of buildings. Tsunamis have also been reported at locations along the Mediterranean coast, including Acre, Jaffa and Gaza, and were generated by approximately $15 \%$ of earthquakes reported in Israel's vicinity (Turcotte and Arieh [1986]).

Another secondary effect of earthquakes relates to flooding, due to the collapse of dams, creation of artificial dams, or to destruction of large containers storing liquids ("seiche"). The effects of spilled toxic chemicals can be severe, too.

Other losses of consequence can relate to fires (conflagration) resulting from the breakage of gas pipes, from explosions, and from the collapse of buildings in which fires are still burning. Fire damage can be substantial due to the difficulties in operating emergency services: inability to call the fire brigades, difficulties in reaching the area, shortage of water due to broken pipelines, etc. Certain earthquakes have been reported to cause fire damage which exceeded the direct loss from the earthquake itself; $80 \%$ of the damage in the 1906 San Francisco earthquake was caused by fire. Similar effects have been observed also in Japan (Japan report, p. 46).

The damage to lifelines can be enormous, affecting water, gas and electricity supplies and interrupting telephone services, other communication and transportation systems, and damaging bridges, tunnels, railways, ports, etc.

1.5. Earthquake losses: Most earthquake losses are related to the destruction of structures (loss of lives typically results from this cause as well). In Mexico's 1985 earthquake, for example, direct property damage accounted for $87 \%$ of the overall loss. However, earthquake losses can be quite diversified. Typical earthquake losses are listed in Table 1 , which is taken from Boissonnade and Shah [1984]. It shows that losses can be direct and immediate (bodily injuries, loss of lives, and property damage, as described above). In some cases, immediate indirect loss may result from the possibility of neighboring enemies taking advantage of the disaster, thus threatening the physical survival and political survival and political independence of the country; other losses can be indirect and may be discovered only in the long run. Long-term secondary effects may be observed in many fields: population migration (especially due to repeated quakes), unavailability of construction materials and skilled labor, contamination and disappearance of water resources, toxic contamination, due to damage to nuclear facilities, etc. Other macro-economic effects could be unemployment (which also creates consequential losses to the business community), changes in the exchange rate, balance of payments deficit, increased external borrowing, unfavorable developments in the capital markets, etc. A major earthquake could affect the entire national economy and could cause regression of several years in the economic development of a poor country and its external debt. 
1.6. The overall expected loss: The expected loss is a compounded function of frequency and severity. The reinsurance pricing techniques take these factors into consideration. Therefore, it is worthwhile to analyze common rating formulae - which are basically quite similar (we have chosen the Munich-Re rating system, see World Map of Natural Hazards, pp.9-13).

Engineers often evaluate the risks by analyzing the possible magnitude, the expected epicenters and the resulting accelerations. This approach enables reaching estimates for specific structures and sites. For general insurance purposes a less detailed approach is needed and, therefore, the basic earthquake risk of an examined region is measured by the maximal intensity of the earthquake. A standardized frequency is estimated describing the number of events which could occur with an average return period of 50 years (such a period represents the typical economic life of a building). The return period is a stochastic variable. Assuming a Poisson distribution, there is an $18 \%$ chance for a gap between quakes of 10 years or less, $39 \%$ for a 25 year gap or less, $64 \%$ for 50 years or less, $86 \%$ for 100 years or less, $99 \%$ for less than 250 years.

The world is divided by the Munich-Re method into 5 risk zones, according to expected earthquake intensity (Mercalli scale).

\begin{tabular}{cc}
\hline Zone & Intensity \\
\hline 0 & V and below \\
1 & VI-VII \\
2 & VIII \\
3 & IX \\
4 & X and above \\
\hline
\end{tabular}

This rating is applied for average subsoil conditions (firm sediments). Local subsoil conditions change the zone's rating as follows:

\begin{tabular}{lc}
\hline Subsoil & Average Change in Intensity Zone \\
\hline Rock (granite, basalt) & -1 \\
Firm sediments & 0 \\
$\begin{array}{l}\text { Loose sediments } \\
\quad(\text { sand, alluvial deposits) }\end{array}$ & +1 \\
$\begin{array}{l}\text { Moistened sediments } \\
\quad(\text { artificially filled ground) }\end{array}$ & +1.5 \\
\hline
\end{tabular}

Soft, water saturated, sediments enhance the ground movement, and may have very damaging effect especially on high-rise buildings (see the Mexico 1957 and 1985 experience).

There are tables describing the expected losses in an affected area, according to the intensity of the earthquake and the construction methods used. Such a table is proposed by the Munich-Re and is reproduced here. Other sources propose quite similar tables (Mann [1984], Bader [1983], Boissonnade and Shah [1984], Fig. 3.4, p. 239). A study by Bader 
compared the building damage factors which are used by the Factory Mutual, and by the Pacific Rating Organization, to other estimates obtained for specific buildings, and found a fairly good fit (See Bader, p. 28). These factors are quite similar to the Munich-Re table.

This table may be used to evaluate the risk of a specific building (see example below). It could also be used to evaluate the expected losses of an entire region, according to the proportion of buildings in the various construction groups.

Table 2: The Expected Property Loss (EL) At Relevant Intensity

\begin{tabular}{|c|c|c|c|c|c|c|c|}
\hline \multirow[t]{2}{*}{ Construction Method } & \multicolumn{7}{|c|}{ Loss Expectancy (\%) at Intensity (MM) } \\
\hline & VI & VII & VIII & IX & $\mathrm{X}$ & XI & XII \\
\hline $\begin{array}{l}\text { 1. Modern, built so as to } \\
\text { resist extra strain } \\
\text { imposed by earthquake }\end{array}$ & - & 1 & 5 & 20 & 50 & 80 & 100 \\
\hline $\begin{array}{l}\text { 2. Modern, not built so as to } \\
\text { resist extra strain }\end{array}$ & & & & & & & \\
\hline imposed by earthquake & - & 5 & 20 & 50 & 80 & 100 & 100 \\
\hline 3. Bricks and wooden frames & 1 & 10 & 40 & 80 & 100 & 100 & 100 \\
\hline 4. Primitive structures & 5 & 20 & 70 & 100 & 100 & 100 & 100 \\
\hline
\end{tabular}

Building contents

(with reference to the

$\begin{array}{llllllll}\text { EL for the building) } & 1 / 5 & 1 / 4 & 1 / 3 & 1 / 2 & 2 / 3 & 4 / 5 & 9 / 10\end{array}$

Source: Munich-Re: World Map of Natural Hazards.

Example: Assume a high-rise building, standing in zone 2 (intensity VIII on the Mercalli scale). The expected loss for such a building in such a quake would be $5 \%$. If we assume that the earthquake frequency in this area is represented by an average return period of 25 years (twice the standard of 50 years), the loss expectancy in 50 years should be multiplied by 2 , i.e. , $10 \%$. (Theoretically, the multiplying factor should be larger than 2 due to probabilistic considerations.) The building standard could now enter the calculation. If it is above standard - according to the engineer's evaluation, the expected loss would be, say, only $6 \%$ rather than $10 \%$. Other specific risk factors are added and subtracted. For example:

a) $20 \%$ extra for tall buildings (above 10 floors). Such buildings may be affected by distant earthquakes due to resonance.

b) $20 \%$ extra for being in city-center area (due to the risk of buildings of varying heights and vibration frequency crashing against each other; see the Munich-Re - Mexico 1985 report).

c) Extra premium for contents, according to pre-set coefficients (e.g., 0.33).

The overall premium for the building without contents according to this calculation would be $8.4 \%(1.4 \times 6 \%)$ for 50 years, or $0.168 \%$ per year.

\section{The management of the earthquake risk}

The risk management literature emphasizes the importance of balanced solutions to problems, and especially the use of loss prevention and risk assumption techniques as a sub- 
titute for insurance (and sometimes as a complementary means). The management of the risk takes place before, at, and after the loss, and is, therefore, based on experience and on social, economic and political planning.

Any risk management decision and any decision to build a certain structure entail in practice an implicit decision about the acceptable risk level. In order to reach a high level of rationality, explicit standards and clear preferences have to be set. Loss prevention standards should be determined only after explicit rules concerning the acceptable level of risk have been agreed upon. Otherwise, it is quite probable that the economy as a whole is suboptimizing; it may be spending too much (or too little) on tough building standards these costs remaining hidden, and not being reflected in any national account. For example, it is possible that Ruritania could buy global earthquake insurance coverage for, say, $\$ 20$ millions, while it spends hundreds of millions of dollars on too stringent construction standards.

The rules concerning the acceptable risk levels must consider parameters such as:

a) The type of building, and its vulnerability to earthquakes.

b) The expected economic life of the building.

c) The potential consequential damage: the value of the use and the value of the building and the importance of having an uninterrupted service. Special structures must have special levels of acceptable risk: hospitals, schools, dams, reservoirs, life-line systems, tunnels, bridges, ports, computer centers, nuclear facilities and waste storage, etc.

d) The subsoil conditions.

e) Earthquake history in the area (frequency, distribution of magnitudes, accelerations, interaction with geological structure, etc.).

In order to obtain some perspective concerning the acceptable risk level, it is useful to mention Costello's comments $(1985$, p. 39$)$ : a $1 \%$ chance is the probability of a destructive earthquake in California (an average return period of approximately 100 years). This is also the chance of dying of a disease, and the chance that a dam builder usually takes in his calculations. The probability of a strong earthquake on the East coast of the U.S. is approximately 0.001 . The chance of being killed in a car accident is 0.0001 , and the probability of dying from force majeure (say being hit by lightning) is approximately 0.000001 .

Common risk management options are:

Avoidance: Earthquake risks could be avoited to some extent by simply not building in certain zones with high seismic hazards, and avoiding activities which are assumed to be more vulnerable due to their risk exceeding some acceptable level.

Prevention: Certain risks could be reduced by using prevention techniques. Unlike common insurable risks (such as fire) which could be prevented, or confined at or after the occurrence of a loss, an earthquake cannot be stopped, and its damages cannot be confined. Therefore, all actions must be taken in advance, and especially through a careful design of structures in order to control their damagability [see Bader, p.22]. Building standards could dictate the materials to be used, the construction methods, and other parameters which affect the resistance of the building and its finishing to the earthquake risk. 
Most countries located in earthquake-prone zones have adopted special zoning regulations and building codes, which are designed to reduce and even eliminate the potential losses. Other countries adjust their standards according to the experience of these countries. Israel adopted the standard T1413 from 1979, which is, in essence, a copy of the California standard (the latter has meanwhile been changed, but Israel is still sticking to the old version). It is believed that such standards, if they are adjusted to specific local conditions in each country, and if they are observed and enforced, are capable of providing protection against fairly strong earthquakes (see New Zealand and Japan reports). The major earthquake damages reported in history, including those that have happened in recent years, related to buildings of poor quality (Managua) or bad ground conditions (Mexico City) and to environments where earthquake building codes do not exist or are not strictly enforced.

Most zoning regulations and building codes are designed to prevent or reduce the possibility of collpse, in oder to enable rescue operations and to mitigate the risk of bodily injuries and death. These codes, however, do not necessarily eliminate the possibility of a major property loss (sometimes a constructive total loss results from the need to destroy partially damaged buildings).

Building codes are often confined only to the zones for which historical records show seismic activity - despite the fact that an earthquake may hit unlikely areas, and have unexpectedly strong intensities (Picard and Froind [1965]). It should also be remembered that due to differences in the geographical spread of risks a mild earthquake hitting a wide area (say the Mississippi valley in the U.S.) may cause greater damage, in comparison to a strong earthquake hitting a small area (say, the San Francisco area).

Insurance: Buying insurance may often be the least expensive solution for the individual, and the country as a whole, especially when world reinsurance rates are determined according to worldwide experience, not necessarily reflecting the risk of the specific zone.

Insurance, however, only reallocates the financial losses, and does not create the real resources needed for complete recovery from a disaster. Earthquake losses often cannot be recovered simply by financial compensation. The problem is that of a real loss of physical resources and property; therefore, the most appropriate counter-measure is to physically protect these assets.

Overall planning: The management of earthquake risk should not be confined to preventing the collapse of buildings. The risk management process must devote much good thinking and planning to the design and use of the economy's infrastructure and organizational structure. It must include loss prevention activities as well as preparedness and early warning activities, comprehensive planning of the rescue and recovery activities, pre-planning of priorities and allocation of emergency resources for quick recovery.

Due to the low frequency of earthquakes, the allocation of actual resources should be combined with other emergency arrangements (in oder to avoid having substantial resources tied up in the project and waiting idle for the earthquake to occur). Due to the complexity of the earthquake risk, the planning procedure must be based on a multidisciplinary team - including experts on technological issues, such as engineers, fire fighters, hazardous materials experts, communications and transportation specialists, medical professionals, etc., as well as economists and legal, financial, social, psychological and political experts. 
An example of earthquake preparedness can be found in Japan (see Japan report, p. 60). In certain areas the seismographs are supposed to automatically activate certain systems - interrupt electricity and gas supply, operate the traffic lights in a special manner, activate automatic flooding of oil tanks with $\mathrm{CO}_{2}$ gas, etc.

\section{Earthquakes in Israel}

3.1. General: Israel is regarded as being in a moderate earthquake zone. The area is affected mainly by seismic activity along the Syrian-African fault (the Jordan Valley, Dead Sea, Gulf of Eilat). Near Sharm-El-Sheikh in Sinai, some $300 \mathrm{~km}$ south of Eilat, there is currently an active seismic zone which, fortunately, is of little importance due to its distance from centers of Israeli population and industry. Israel may also be affected by earthquakes in the Mediterranean, or in Turkey. Most earthquakes which have occured in the Mediterranean during this century have not left any significant effects. However a tsunami could cause some damage in the Haifa and Tel Aviv areas.

In recent years seismic studies of Israel have improved, due to the installation of more sophisticated equipment (seismographs and accelerometers). The measurement of accelerations indicate that the geological structure of Israel generates faster attenuation than assumed earlier. However, other evidence, concerning the activity of secondary faults, besides the one in the Jordan Valley, may indicate a higher level of activity than previously thought.

3.2. Return period: Most studies of the seismic risks in Israel are based on various historical, non-instrumental evidence, and are, therefore, of limited value only in cataloguing earthquakes (Amiran [1950]; Ben-Menachem; Picard and Froind [1965], and others). A draft of the most recent catalogue was prepared by Turcott and Arieh [1986], and lists 64 significant earthquakes in the region of Israel and its vicinity (Lebanon, Syria. Jordan) during 2000 years (i.e., an average return period of $35-50$ years). These studies are subject, of course, to substantial uncertainty concerning the occurrence itself, the estimation of its magnitude, the intensitites in various sites, etc.

The reciprocal value of the "return period" statistics should be interpreted as representing a parameter of the loss frequency distribution. In our simulations we applied the Poisson distribution, though other distributions could be fitted to such statistics as well. A Poisson model assumes that earthquake occurrences are independent and identically distributed. The probability for having $k$ earthquakes during the time interval $(0, t)$ is:

$$
P(N=k)=\frac{e^{-\lambda t} \cdot(\lambda \cdot t)^{k}}{k !}
$$

where $\lambda$ is the mean earthquake frequency (for earthquakes of magnitude greater than $\mathbf{M}$ ). A large number of references use this model. Shpilberg and Pinedo [1979], however, question the assumption of independency (i.e., the assumed lack of memory), and used the continuous time Markov Chain and an alternative linearly increasing hazard rate model which are claimed to have a better explanatory power of historical records.

3.3. Insurers estimates: The ROA estimated that Israel has experienced on the average 2-5 earthquakes of intensity VI/VII or more on the Mercalli scale, during every century (i.e., a mean return period of 20-50 years). It is possible that one or two were of intensity VIII (see ROA). Most of the earthquakes occurred along the Jordan Valley. Following 
seismological research, the ROA and the Munich-Re assumed that Israel could be exposed to a strong earthquake once or twice during 50 years and the intensity would be Mercalli VII. All sources believe that the earthquake magnitude for Israel's region is between 7-8 on the Richter scale.

More recently Cresta (an association of large world reinsurers) evaluated the mean return periods of an earthquake at any point in Israel as follows:

\begin{tabular}{cc}
\hline Intensity (MM) & Mean Return Period \\
\hline VII & 140 years \\
VIII & 500 years \\
IX & 2100 years \\
\hline
\end{tabular}

These figures reflect the belief that Israel is located in a moderate earthquake zone (compared to Mexico, for example, where 34 earthquakes with magnitudes exceeding 7 were recorded during this century alone within a radius of $650 \mathrm{kms}$ around Mexico City).

3.4. The validity of insurers estimates: The insurers estimates may be highly biased due to two distinct factors:

a. Sub-zones probabilities: The mean return period estimates which are used by the insurers are probably biased since they relate to the entire country as one region and ignore the possibility that only part the country will be affected by the earthquake. An estimated mean return period of a quake of intensity VII or more - for any point in Israel - must be higher than the country's rate.

When talking about the probability of an earthquake, one should take care to define the relevant area referred to. The probability of an earthquake in the Middle East, for example, is larger than the probability of an earthquake in, say, Israel, and the latter is larger than the probability of an earthquake in any given region in Israel. Historical evidence of earthquakes in Israel and its vicinity should not be misinterpreted to indicate the same high probabilities for any specific sub-region (see below).

b. The investment income effect: A second problem with the common ratemaking techniques, besides the use of the irrelevant probabilities, stems from ignoring the expected accumulated investment income. When talking about 20-30 years accumulation, the interest factor may be substantial and the accumulated amount could easily be doubled (for a real annual interest of some $5 \%$ ). Thus the insurance rate should be reduced again, this time by a factor of approximately 2 . Note that such discounting should take place independently of the question whether a special reserve is actually being maintained or not. 


\section{Figure 1}

Comparison of isoseismal contours for the1906 San Francisco, Calif., and 1811 New Madrid, , Mo., earthquakes. The contour lines connect sites having the same value of Modified Mercalli intensity, a numerical index of effect of an earthquake on man, the Earth's structure, and on buildings. The New Madrid earthquakes were felt over almost 1 million square miles and produced damage ranging from minor structural and architectural damage (MM intensity VII) to total destruction (MM intensity $\mathrm{X}$ to XII). The San Francisco earthquake, in comparison, was felt over 60,000 squares miles. (From Thiel and Morelli [1982].)

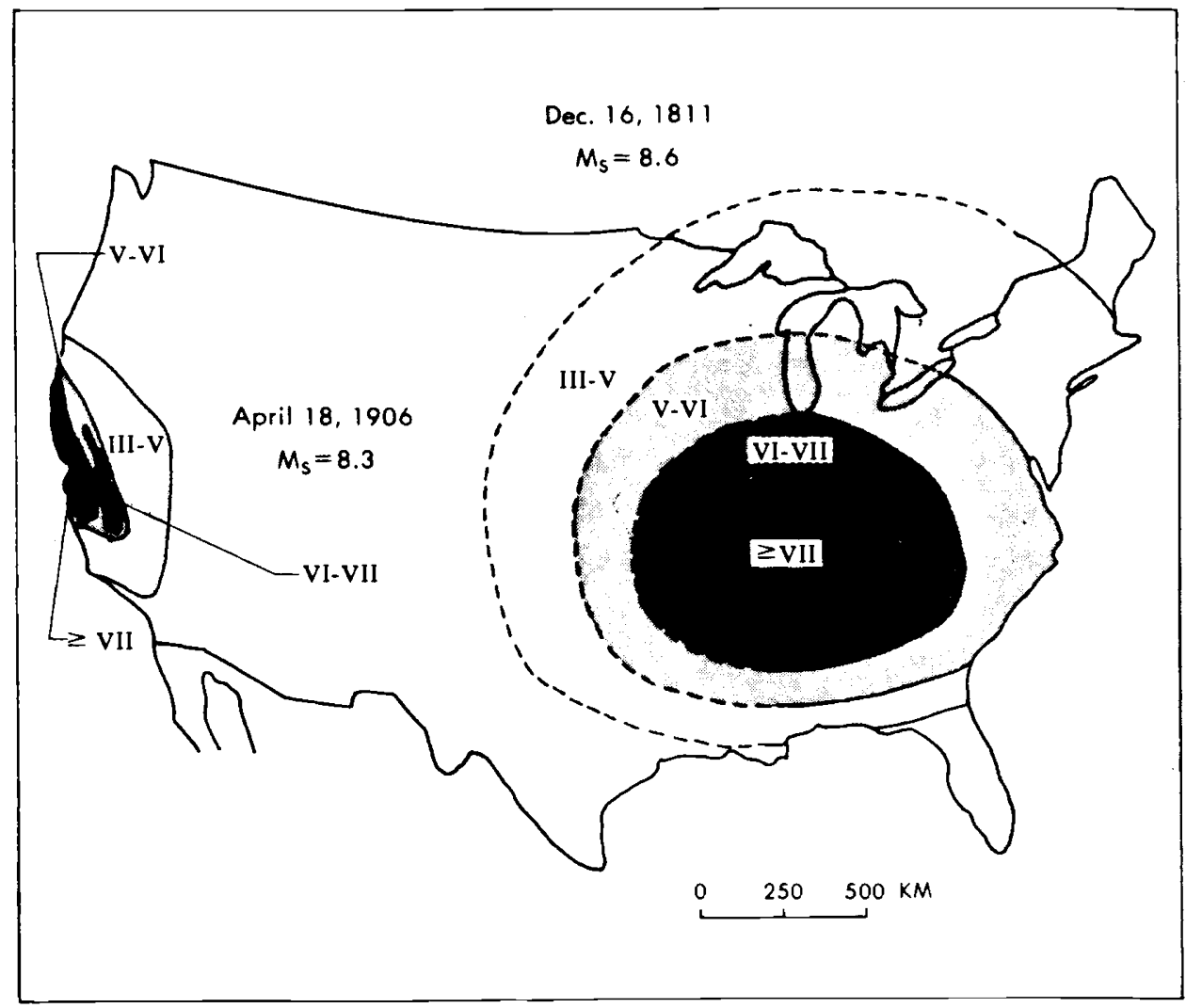


3.5. The affected area: The total area over which a major earthquake is felt is much larger than the area suffering damages. Earthquakes in other countries are felt in widely spread areas, depending on their magnitude and the geological structure of the affected area. Thiel [1982], for example, states that the 1906 San Fransisco earthquake was felt over a territory of 60,000 square miles, whereas the New Madrid earthquake (1811) affected 1 million square miles (see Figure 1). Even if we accept the zone rating, one should consider the probability of any specific sub-zone being affected by the earthquake. The probability of a certain zone being hit by an earthquake depends on the probability of the country being hit and the conditional probability of that area being hit, given an earthquake in the country. With the use of the (unrealistic) assumption of independence, the probability of that area being hit is a product of the two numbers. For example, Israel is ranked by reinsurers to be in zone 1 of the Munich-Re scale (earthquake intensity VII) with an average return period of 25 years, i.e., the corresponding Poisson probability for the country to be hit is 0.04 . The return period was calculated by using the historical record of a broad region. Therefore, we argue that these figures should not be interpreted as meaning that every single spot in Israel will be hit by these earthquakes.

The fact that earthquakes hit a limited zone is not considered by the common insurance rate making formula, and this leads, in my opinion, to an exaggerated loss expectancy figure, and thereby to excessive rates. For example the isoseismic maps of the strong earthquakes in 1837 and 1927 (see Figure 2) show that earthquakes of the maximum intensity hit relatively small areas - having a radius of some $20-30 \mathrm{~km}$. Neighboring areas were hit with weaker intensities - causing insignificant damages only. This means that if the earthquake hits the area with a maximum intensity of VII around the epicenter the area of the affected zone will be approximately $2700 \mathrm{~km}^{2}$, which is only one eighth of Israel's area. (The shape of the isoseismic zones is not necessarily circular. We use the idea of a circle just for demonstration purposes.) In other words, if the epicenter is randomly distributed over the country (an unrealistic assumption), the probability to be considered is $0.005(0.04 / 8)$ which is only one eighth of the figure considered originally.

If the expected average loss is $5 \%$ of the total property in the affected zone, and the probability for the zone to be affected is 0.005 , the expected loss under the above assumptions will be approximatelyf 0.00025 (compared to the rate in Israel, which at present is 0.0004 ). This figure could serve as a rough indicator for the required net insurance premium and it should be even lower, taking the investment income into consideration. Note that the Cresta estimates for the earthquake frequency are much lower than those assumed here and, therefore, imply much lower rates.

The key question in assessing Israel's vulnerability is whether the country should be regarded as a single earthquake zone, or should rather be divided into several distinct risk zones. The consensus today seems to be that the country should be divided into zones such as north, coast-line, center and south (see Figure 3). Due to the small size of the country, an earthquake in one area may be felt in the others but will not necessarily have damaging effects.

The evaluation of the earthquake risk in practice is more complicated. The distribution of the intensity level should be considered, and a more sophisticated damage function 
Figure 2

1soseismic map of the Nablus earthquake of 11.7.1927

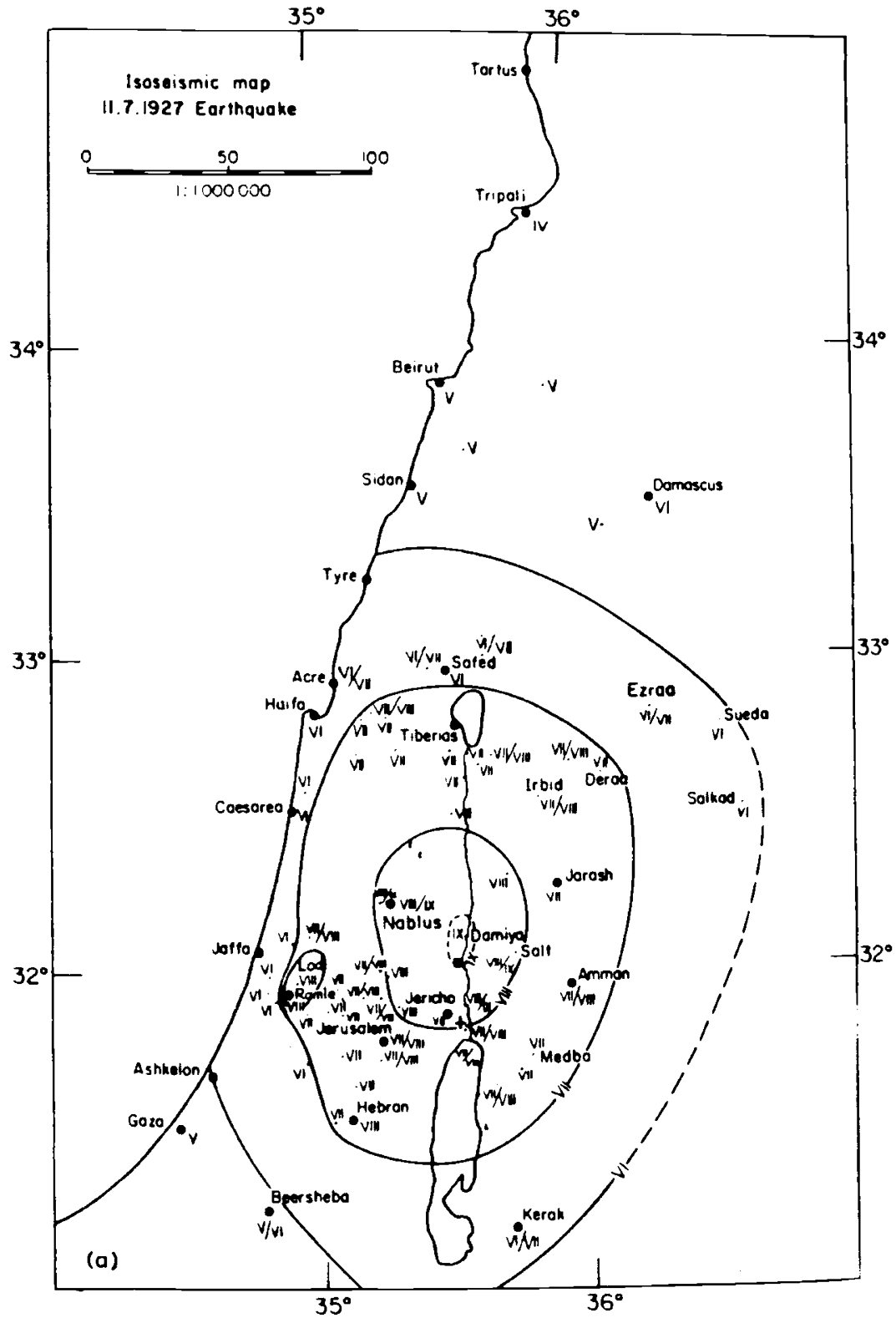

Source: A. Ben-Menahem TECTONOPHYS1CS (1980) 
Figure 3

1soseismic map of the Safed earthquake of 1.1.1837

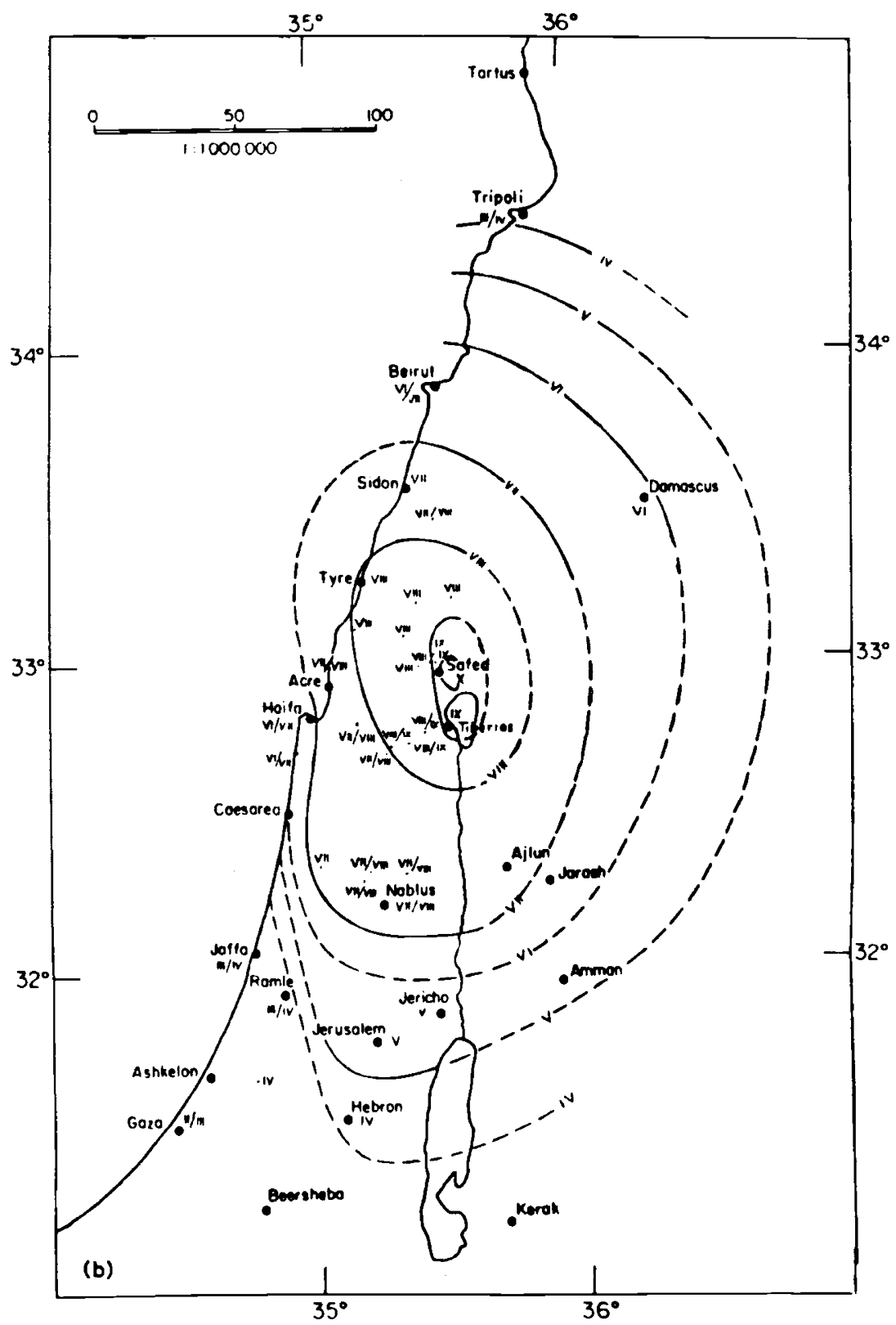


(depending on the earthquake's magnitude, the specific types of structures in the affected area, and their vulnerability levels) should be analyzed. Some trials in this direction were recently suggested by Arieh [1985] who tried to impose the distribution of intensities of various earthquakes on a single map.

The conditional chances of a certain zone being hit, given an earthquake in the country, are also dependent on the (stochastic) earthquake magnitude level. Due to non-uniform distribution of property in Israel, the MPL should be measured carefully. An earthquake in the Tel Aviv region, for example, may affect $60 \%$ of the country's assets. Certain simplified simulations were carried out to describe the combined effect but are not reported here.

Note that the estimates of an earthquake's damage are extremely sensitive to the earthquake magnitude assumption. A stronger earthquake increases the expected loss in two ways: it increases, of course, the damage in the affected area (a more than linear increase) but also increases the radius of the affected area itself, thereby increasing the area dramatically (a power of two of the radius). If the earthquake is of stronger magnitude (generating a maximum intensity of VIII) the radius of the area hit by intensities VII and VIII is much larger, say, some $40-50 \mathrm{~km}$. In such a case the affected area would already cover one quarter to one third of Israel's territory. In such a case the probability of a specific point in Israel being hit by such an earthquake would be $2-3$ times larger. At the same time, the higher intensity would mean a much larger average damage in the affected areas.

3.6. Vulnerability of specific regions: The potential effects of an earthquake in Israel are determined mainly by its magnitude, the distance from the epicenter and the geological structure. The most vulnerable areas are those with alluvium rock and soft sediment rock (especially the sloped ones), and those areas having underground water near the surface. The vulnerability of all zones in Israel has been analyzed but is not reported here due to the very specific nature of these data (for more details, see Picard and Froind [1965] and ROA [1976] pp. 13-17). These estimates are subject, of course, to reassessment in view of the improved geological and seismic data at present available.

\section{Earthquake insurance: key issues}

This section attempts to summarize some of the key dilemmas related to the issue of earthquake insurance.

4.1. Are earthquake losses insurable? Even in the absence of a special earthquake insurance coverage, part of the losses are, anyhow, covered by the private insurance industry through life and disability insurance policies, medical insurance, employers' liability, loss of profit insurance, automobile property damage coverage, and liability policies of construction companies, architects and engineers. The question is whether the earthquake risk can be directly insured.

Due to the catastrophic nature of earthquakes, and the difficulties associated with the assessment of the probability and intensity of potential losses, such risks are often regarded as being commercially uninsurable. Others believe that earthquakes are an insurable risk, and in pratice sell commercial coverage (see the discussion of limits to insurability by Berliner [1982]). Even when regarded insurable by commercial insurance, the risk is often 
beyond the capacity of the domestic insurers in the country, and they have to rely heavily on the international reinsurance markets.

4.2. Who are the insurers? Should earthquake insurance be nationalized? When considered uninsurable, the economy has no choice but to assume the earthquake risk (either by each individual separately, or by the goverment, through certain emergency assistance programs). In modern economies the government usually takes responsibility for recovery and in such a case some sort of national insurance program is put into operation (either implicitly or explicitly).

Often, governments participate in the commercial insurance - usually by assuming parts of the top reinsurance layers. This turns out to be a very efficient way of dealing with earthquake risk. The government would anyhow be called to step in and compensate the uninsured victims - and it would be politically unable to ignore such calls.

It is advisable to establish the rules for government interference in advance. It could take the form of direct help to victims or guaranteeing of government involvement as a reinsurer of the top risk layers where international insurance capacity is exhausted. Such a solution has been proposed by the Reinsurance Association of America, which called to found a Federal Earthquake Catastrophe Reinsurance Corporation to respond to the availability problem of large earthquake insurance. Some countries (e.g., Japan) have already acted in this direction.

The structure of the Japanese earthquake market is as follows (Japan report, p. 56): the first layer is covered by a local pool, the second layer by the local insurers (plus reinsurance), the third layer is covered half by insurers and half by government, while $95 \%$ of the top reinsurance layer is covered by government. In the Japanese case, only commercial risks are insured through the private sector, whereas homes are generally insured by a governmental program. This reduces the demand of the Japanese market for external international reinsurance.

4.3. The form and extent of "nationalization": The above discussion demonstrates that the relevant question is typically not whether to nationalize earthquake insurance, but rather the extent of the nationalization - whether the government should take a major part or rather a small share of the risk. A recent proposal made by the Israeli insurance industry strongly resists the possibility of government intervention in earthquake insurance, but at the same time calls for basing the solution on government participation in the reinsurance, in addition to its financial aid - issuing special government bonds. In my opinion this is nothing but another form of nationalization.

The loss of lives and physical resources following an earthquake cannot simply be recovered by financial indemnity. Money that will come from foreign reinsurers will ease the situation in many cases but will often be insufficient to solve the severe problems associated with shortage of physical resources, manpower, etc. It may often just lead to price increases similarly to the effects of printing of money by the government. The earthquake insurance problems thus resemble dilemmas of large national schemes such as the social security which faces the need of guaranteeing social security and retirement income for the entire population and has to decide whether to finance the program by a cross-subsidization ("pay as you go" approach) or rather through a "full funding" system. In such schemes, the rules of commercial insurance are not necessarily applicable. 
The form and extent of government involvement is determined by the answers to the following dilemmas:

a) Whether to make earthquake insurance compulsory.

b) The choice of the specific agency (private or governmental insurer).

e) The method of indemnification and allocation of the compensation.

d) The attitude towards reinsurance.

4.4. Voluntary or compulsory coverage: When insurance coverage is sold on a voluntary basis, only those feeling that they might be affected by the risk will buy coverage. This tends to generate adverse selection against the insurers, and may, besides, generate a premium volume which, in the case of earthquake risk, will be insufficient to support overall national protection schemes.

The problem will be componded if the property owners believe that in case of loss the government will anyhow assist them, independently of their having earthquake insurance. In such a case, those who have bought insurance will regret the purchase - since everybody is being compensated anyhow.

It follows that compulsory coverage is needed in order to assure that everybody is covered and in order to guarantee a just allocation of compensation, which normally will be at least partially financed by national programs. Indemnification must be granted according to professional considerations and has to be free of the potential political pressures following a disaster. Not having compulsory coverage schemes makes for political pressures on the government (on behalf of the uninsured) following a disaster.

Compulsory coverage may be implicit - through the automatic inclusion of the earthquake risk in the standard homeowners policy - as is the case at present in Israel. (This is probably a remnant of the old British policies which were adopted by the Israeli companies. The inclusion of earthquake coverage in these policies probably reflects the low earthquake risk in England.) Compulsory coverage would be necessary in order to guarantee that the uninsureds would be ineligible for any kind of support. This is essential for the success of the program (see the success of the Israeli program for the coverage of natural risk in agriculture).

Unless compulsory, most property owners do not purchase earthquake insurance. Kunreuther [1973, 1974, 1978] showed that, even in earthquake-prone zones, people are unaware of the hazard and of the insurance needs, and are quite ignorant of the availability of insurance schemes.

This behavior is explained by the individuals' psychological motives; Kunreuther found that people try to reduce their worries and anxiety level, and, therefore, whenever they face undesired events with small probabilities, they implicitly assume that the probability is zero and ignore the threat. In other words, people do not take any steps towards loss prevention or insurance purchasing since they have a tendency to under-estimate the probability of being affected by an earthquake. The attitude of corporate risk managers towards the carthquake risk may be even more resentful. They are expected to pay little attention to low probability/high consequence risks for they reap no reward for reducing these risks, and may even be penalized for initiating expenditures on insurance or loss prevention activities of such exposures (Kunreuther [1978], Katzman [1985]).

These findings do not support the hypothesis that people avoid purchasing coverage since they rely on governmental assistance in case of loss. Kunreuther showed that people 
did not plan ahead for earthquake contingencies, and, therefore, they naturally did not plan to ask for government assistance, often being even unaware of such a possibility. Many did not apply for such assistance even after being hit by an earthquake.

Such findings lead to the conclusion that earthquake insurance has to be compulsory. Not purchasing insurance is the result of consumers' "mistakes" and the authorities should adopt a patronizing attitude to correct these mistakes. If the choice has to be made between post-loss rehabilitation loans and a compulsory insurance coverage (which is naturally purchased prior to the occurrence of a loss) the latter option is preferable from the natural point of view - since the choice is between financing loans which will not be paid back and insurance which will be financed through premiums that will be collected from everybody, even when no disaster occurs.

Additional benefits of compulsory insurance are related to its abiliby to support joint public loss prevention activities (see the example of the U.S. FAIR flood insurance program) and to the educational effect of an insurance scheme. (Note that in the past people did not buy fire insurance until they were forced to do so by the mortgage banks. Today such coverages are purchased voluntarily.) The insurance agents would serve as an instrument for technological transfer, and for increasing the awareness of the entire population to the risk.

The ideological, normative resistance to compulsory coverages could be softened by viewing insurance schemes as a non-bureaucratic mechanism for handling losses, which replaces governmental regulation (see Katzman [1985] p. 151). Moreover, the need for profit-motivated marketing, through the private sector, prevails even for a compulsory coverage - especially due to the above-mentioned educational effect.

4.5. The agency: private or governmental insurance? Earthquake insurance is in any case partially handled by the government and the question of government involvement is simply one of form and extent.

A joint operation with the private insurance industry is beneficial, especially in the areas of ratemaking, marketing (even when the program is compulsory), and in the settlement of losses.

Loss settlement by private insurers guarantees that compensation is allocated on a professional basis, independently of political pressures. In the case of a major earthquake, however, the situation does not enable an orderly assessment and evaluation of each individual loss to satisfy the private insurers needs; the main initial efforts are devoted to emergency rescue operation, and attemps to resume a reasonably normal life as soon as possible. Moreover, the financial indemnification by private insurers does not always guarantee the availability of the required materials and physical resources needed for rehabilitation.

Therefore, a national emergency program must be prepared - to formalize the legal authority to take emergency action and allocate resources, and to define the role of private insurers and their mode of operation. Due to the low likelihood of earthquakes, there is no sense in having a special earthquake emergency code and there is no justification for creating special agencies for the earthquake risk. A general regulation and plan dealing with all kinds of emergencies (such as earthquakes, nuclear risks and agricultural risks) is more likely to be recommended. Israel does yet have such legislation. 
4.6. Reinsurance: A small country is often unable to deal alone with large-scale risks due to the inability to reach domestically a full diversification of the risks. It must rely, therefore, on international risk-bearing capacity. However, small developing countries are often in financial distress and do not have the foreign exchange needed to buy reinsurance abroad, Some countries even prohibit the transfer of foreign currency, including those funds needed for the purchase of reinsurance. Such prohibition is based on a misconceiving of reinsurance premiums as imports. Only part of the reinsurance premiums should be defined in the National Accounts as an import; in the long run, if the insurance is appropriately priced, the true cost of reinsurance is only the "loading " on top of the expected loss - say $20 \%$ of the premiums. In the Israeli case - with annual reinsurance premiums of the order of $\$ 15$ million, the net annual cost would be around $\$ 3$ million. This is a small price for the advantages accruing from international risk diversification of such serious risks.

The above arguments do not hold when the reinsurance is not priced properly and tends to be overpriced. The net cost to the economy could become excessive and in such a case the government would be fully justifed in preventing the transfer of reinsurance premiums.

Some developing countries try to reduce the outflows of foreign currency by forming a local pool which absorbs most of the domestic risks and reinsures only a residual part of the risk. This has proved to be a useful technique in some cases, where most of the risk could be retained locally (see, for example, the case of automobile insurance through the AVNER pool in Israel).

This, however, is not the case of the earthquake risk; in a small country only a small part of the risk can be retained locally, and the rest must be reinsured. In such a case a pooled reinsurance purchase does not necessarily lead to a saving for the national economy. A contrary effect may even take place: due to the size of the ceded risk, a pooled activity could be too large and result in commercial inflexibility and an inferior market position for the ceding economy. The Israeli example may be used to demonstrate this point: due to the inclusion of earthquake coverage in virtually all policies, Israel - despite its small size and moderate earthquake risk - is a major consumer of earthquake insurance in the world market. This calls for a concerted action of the leading reinsurers against Israel, in setting the rates.

The reinsurance markets are also limited in their capacity. A large disaster, where most of the losses are reinsured, could pose serious capacity and solvency problems to the reinsurers. It must be rememberer that the world reinsurance market cannot be regarded as a supplier of risk-free guarantees for financial support in case of a major earthquake. In other words, a national earthquake insurance scheme cannot in itself be regarded as risk-free! (The 1906 San-Francisco earthquake resulted in bankruptcy of many insurers.)

Therefore, a new approach to the reinsurance of earthquake risks must be developed. Reinsurance may be viewed as a long-term international loan (see Bohman [1985]). Whenever a loss occurs, the economy receives a "loan", which is returned over time in the form of premiums - before and after the loss. Normally, this unusual loan is repaid in advance. Alternatively, a regular financial loan could be secured in case of emergency in the form of a credit line arrangement - which would be repaid after the loss - if such a loss occurs. 
The reinsurance arrangement is profitable to the economy only if its costs are smaller than the financial (and political) cost attached to such credit line arrangements.

4.7. Common terms of earthquake insurance: Earthquake insurance typically contains the following conditions.

1. It is usually impossible to purchase full protection. High deductibles, and upper limits on the amount of coverage are common. In some countries only total losses and ncar total loss (say $70 \%$ and up) are eligible for compensation. Sometimes coverage is limited only to the buildings and is not granted to the contents. Such requirements ease the country's access to the reinsurance markets.

2. There are certain administrative constraints which are designed to reduce moral hazards. For example, in Japan, earthquake insurance may be purchased only at the normal renewal date of the fire policy, and it becomes valid only 7 days after purchase.

3. Often, a limited amount of earthquake coverage is included in the homeowners policy. Additional optional cover may be purchased.

4. Earthquake insurance is sold together with fire policies; this enables cutting marketing costs. In some countries the commission rate on this element is limited (e.g., $2.5 \%$ in New Zeland and in Columbia). This leaves a higher proportion of the premium to cover the risk itself (see Swiss $\operatorname{Re}[1978]$ p. 19).

5. One occurrence is defined as all vibrations and shock within a 48 or 72 hour period. Consequential fire losses and constructive total losses are covered.

6. In many countries only a part of all assets are insured, and often are not covered for their full value. For example, it has been estimated that the insured losses in the 1985 Mexico quake were quite limited, due to severe underinsurance ( $30 \%$ on the average), $25 \%$ self-retention, and lack of insurance for many buildings (including the Mexican government buildings). This is not the case in Israel: insurance contracts are indexed and most properties are insured (including those in poor neighborhoods - due to housing agency requirements).

4.8. Earthquake insurance premiums: Earthquake insurance premiums should be reported separately from regular fire risks to enable special arrangements for this type of insurance (such as commissions, reinsurance, and reserving arrangements).

Due to the wish to limit anti-selection and moral hazard against the (re)insurer, the literature recommends that an attempt should be made for the premium to reflect the true risk. This is rather difficult in the case of the earthquake risk, due to the high level of uncertainty attached to the evaluation of this peril. The classification should attempt to distinguish among various geographical zones, various geological structures and various building standards with rating factors based on the type, height, use and the contents (for industrial structures). However, due to the probability attached to the earthquake risk, the premium rate would typically be low, so that rate differences would be too small in absolute terms, and would not generate a significant incentive for loss prevention activities, and would not stimulate loss prevention activities. Moreover, the setting of differential rates could be quite difficult from an actuarial point of view. This leads towards the recommendation to use a uniform premium rate - which could, perhaps, be subdivided into a number of subgroups by geographical zones. 
In the Israeli case even a rough distinction by zones is not an easy task - considering the small size of the country. (In general, insurers try to avoid setting separate rates for zones smaller than $2500 \mathrm{~km}^{2}$.) Areas with large risk accumulation should pay to compensate for the increased risk.

4.9. Special reserving arrangements: According to common accounting techniques, the entire premium is regarded as a taxable income. Since earthquakes, it is to be hoped, do not occur every year, the earthquake premium should not be considered as earned at the end of a year where no loss occurred. Therefore, the tax considerations encourage ceding a large proportion of the premiums to the international reinsurance markets, where, perhaps, such premiums could be offset by appropriate reserves.

There is a need for tax rules allowing for larger reserves for unexpired risks. Obtaining recognition from the tax authorities of the long-term nature of the earthquake premiums, and permission to keep a large proportion of the earthquake premium as a long-term reserve could serve as an incentive to increase the domestic retention. These rules, however, should be constrained in such a way that domestic insurers will not speculate by taking too-large retention. This policy issue is outside the scope of this paper, but high priority must be given to its handling.

\section{Concluding remarks}

This paper surveyed a large volume of literature, in order to elicit certain elements which seem to be of much relevance to the Israeli environment. The following main conclusions have been reached:

a) The earthquake risk may result in several billion dollars worth of damages in a single occurrence and is capable of triggering tremendous changes in the economy. In addition it may increase the country's vulnerability to attack by surrounding hostile countries.

b) Better understanding and awareness of the risk should be developed, and certain risk management techniques should be applied, especially consistent and well thought out loss prevention and rescue activities, and planned recovery operations. Since risk managers and individuals tend to ignore low probability risk, these problems must be handled by a special national team authorized do deal with the country's preparedness for catastrophes and large-scale emergencies.

c) A general code and set of regulations concerning catastrophes and states of emergency should be prepared. Currently there is no specific law concerning natural disasters in Israel.

d) Earthquake insurance should be compulsory. At present, all those insured by fire insurance policies are automatically covered also for earthquakes. However, uninsureds may still apply for government assistance after a loss, and this should be prevented, by either forcing them to insure, or by making it clear that no aid will be given to the uninsured.

e) Since in case of a major earthquake, the government will anyhow be called upon to assist affected industries and individuals, it should plan its participation ahead and make it explicit. One way of doing this is through participation in an insurance scheme, where the government operates as a coinsurer and, more importantly, takes a major part of the top reinsurance layers. 
f) It has been found that at present almost all structures (residential, commercial and industrial) are automatically covered against earthquake insurance and this makes Israel one of the largest customers of earthquake insurance in the world market. This share should be reduced in order to improve Israel's bargaining position in the world market. This could be achieved by formal undertaking of top risk layers by the government as well as by putting certain constraints on the local coverages - say, an upper limit on the amount of coverage per single property, a higher self-retention by each insured, etc.

g) There is need for a change in the tax rules concerning special reserving for earthquake insurance.

h) There is need for a coordinated effort to periodically reevaluate the earthquake risk, given the improved quality of seismic instrumentation in the country. The increased risk stemming from the growing popularity of high-rise buildings in rapidly growing urban areas should be evaluated.

i) The available information suggests that the current ratemaking techniques used by the international reinsurers lead to overpricing the risk due to two major errors:

(1) An overestimation of the probability of each specific point, within a large geographical region, being hit by a severe earthquake.

(2) An overestimation of the cost - due to the exclusion of the investment income from the ratemaking formula. In lines with a mean return period of 50-100 years, this factor leads to overestimation of the rates by a factor of 2-4 times. In addition, insurance rates may be biased as a result of an improper treatment of the stochastic nature of the risk, and especially the time-dependent feature.

j) More attention should be given to the recent experience of other countries, and the implications for construction codes and standards. The 1985 Mexico earthquake showed the insufficiency of their improved 1976 standard. In addition it highlighted the major problems resulting from rapid urbanization and the growing popularity of high-rise buildings - which may dramatically increase the vulnerability to earthquakes (in terms of both frequency and severity of the damage). As a result, recordings of intensities in former earthquakes, should be used with much care when applied to modern cities, especially those located on low-quality soil.

The experience from other quakes shows the many possibilities of improving the earthquake-resistant characteristics of buildings. This experience should not only be used by the engineers, but should be brought to the attention of urban planners and decision makers in municipalities - and should serve as a source of additional parameters in their decision making. This could affect decisions such as the direction of the major axis of buildings and roads, the use of buildings (allocation of weight in the building), the reinforcement materials and methods, and even the use of certain decorative elements (marble facading etc.).

k) As a final note, it should be mentioned that the discussion in this paper implicitly assumed that the country should handle its own risks. Clearly, a lot can be gained from international funds which should be set up for the purpose of mitigating the effects of extraordinary hazards. 


\section{REFERENCES}

AMIRAN, D.H.K. [1950]: "Earthquakes" (Hebrew), 1srael Exploration Journal.

ARIEH, E. and FELDMAN, L. [1985]: "Seismic intensities of earthquakes in Israel and adjacent areas during the last 2000 years", draft Z1/567/79/(35), The Institute for Petroleum Research, March 1985.

ARIEH, E, and ROTSTEIN, Y. [1985]: “A note on the seismicity of Israel (1900-1982)”, Bulletin of the Society of America, 75 (June 1985), 881-887.

BADER, H. [1983]: “A guide to earthquake hazard analysis", Risk Management, (February 1983) $22-30$

BEN-MENACHEM, A. [1975]: "Earthquake risk in Israel" (Hebrew), Weizman Institute, Department of Geophysics.

BEN-MENACHEM, A. [1984]: "Seismic risk in Israel" (Hebrew), Bituah (Insurance), July 1984.

BEN-MENACHEM, A. [1980]: "Variation of slip and creep along the Levant Rift over the past 4500 years", Technophysics, $80,183-197$.

BERLINER, B. [1982]: Limits to Insurability of Risks, Prenctice Hall.

BOHMAN, H. [1985]: "Borrowing money among friends", Zeitschrift für Versicherungswesen, 21/85, 578-580.

BOISSONNADE, A. C. and SHAH, H. C. [1984]: "Seismic vulnerability and insurance studies", The Geneva Papers on Risk and Insurance, 9 (July) 223-254.

BOISSONNADE, A.C. and SHAH, H. [1985]: "Earthquake insurance risk", Earthquake Engineering Center, Stanford University, Report 68 , January.

BOISSONNADE, A.C. and SHAH, H. [1985]: "Use of pattern recognition and fuzzy sets in seismic risk analysis", Earthquake Engineering Center, Stanford University, Report 67, January.

BRODAI, M. [1985]: "Earthquake insurance - A new perspective" (Hebrew), Bituah (Insurance), April, 22-26.

COSTELLO, J. A. [1985]: "Evaluation of site hazards", U.S. Geological Survey, Department of the Interior, Interagency Committe on Safety in Construction. Open File Report 85-371 (ICSSC TR6), Reston, Virginia. Geological Survey Map of Israel.

GERE, J.M. and SHAH, H. [1984]: Terra Non Firma - Understanding and Preparing for Earthquake, Stanford Alumni Association.

GUMNITZ, C. [1974]: Global Tectonic and Seismic Risk, Elsevier, Amsterdam.

HAY, W. [1983]: "Summary report of the workshop on continuing actions to reduce losses from earthquakes in the Mississippi Valley Area", in U.S. Geological Survey, proceedings of Conference XV111, Open File Report 83-157, Reston, Virginia.

INSTITUTE of GEOLOGICAL RESEARCH, Catalogue, Edinburgh.

JACKSON, E. L. and MUKERJEE, T. [1974]: "Human adjustment to the earthquake hazard of San Francisco, California", in Wite G. F. (Ed.). Natural Hazards, Oxford University Press. 
JANAI, S. [1972]: "Earthquake risk in Israel” (Hebrew), Israel Reinsurance Co.

JANAI, S. [1985]: "Earthquake - A risk and a challenge" (Hebrew), Insurance in Israel, May, 11-12.

JAPAN [1982]: Ancillary Perils.

JOHNSTON, A. and NAVA, S.J. [1984]: "Recurrence rates and probability estimates for the nia. New Madrid seismic zone”, in U.S. Geological Survey, Open File Report 84-770, Reston, Virgi-

KATZMAN, M. T. [1985]: Chemical Catastrophes: Regulation, Environment Risk, Pollution, Liability Insurance, Richard D. Irwin Inc., Homewood, Illinois.

KUNREUTHER, H. [1973]: "Recovery from natural disasters: Insurance or federal aid?" Evaluative Studies 12, December.

KUNREUTHER, H. [1974]: "Economic analysis of natural hazards : An ordered choice approach", Wharton Department of Decision Sciences, University of Pennsylvania, Philadelphia.

KUNREUTHER, H. [1978]: Disaster Insurance Protection: Public Policy Lessons, John Wiley \& Sons, Canada.

MANN, C.O. [1984]: "Seismically safe structures and their cost-effectiveness", in U.S. Geological Survey, Open File Report 84-772, Reston, Virginia.

MORIMIYA, Y. [1985]: "Covering national disasters in the Japanese market", Risk Management, December, 18-26.

MUNICH-RE. [1982]: “World Map of Natural Hazards”.

MUNICH-RE.: "Managua - a Study of the 1972 Earthquake".

MUNICH-RE.: "Guatemala 76 Earthquake of the Caribbean Plate".

MUNICH-RE. [1984]: “Are earthquake losses unavoidable?” Schaden Spiegel, No. 1, 101-103.

MUNICH-RE.: "Israel and the Adjoining Middle East States: Earthquake"

MUNICH-RE.: "Countries with State Participation in the Cover of Natural Disasters".

MUNICH-RE. [1986]: Schaden Spiegel, No. 1.

MUNICH-RE. [1986]: Earthquake, Mexico,1985.

Natural Hazards Observer - Various Issues.

NEW ZEALAND [1982]: Ancillary Perils.

PICARD, L. and FROIND [1965]: "Evaluation of seismic risks in Israel" (Hebrew), The Israeli Insurance Institute.

ROA [1986]: “Earthquakes: A general introduction”, Reinsurance Offices Association, London, April. 
ROA [1976]: “Earthquake study: Israel”, Reinsurance Offices Association, March 1976.

ROTH, R.J., HOLTON, R.B. and SAID-ON, S. [1986]: "California eathquake zoning and PLM evaluation program", California Department of Insurance, June.

SHPILBERG, D. and PINEDO, M. [1977]: "Stochastic models with memory for seismic risk evaluation", Risk Theory Seminar, Athens, Georgia, April.

SHENHAV, Y: "Towards an international insurance fund: A tool for mitigation of extrahazard risks" ASTIN Bulletin IX (3), 290-305.

SWISS RE: "A Short Guideline to Earthquake Risk Assessment".

SWISS RE [1978]: "Two Fundamental Aspects of the Earthquake Risk Cover".

THIEL, C.C. and MORELLI, U. [1982]: "Enhancing seismic safety in the Central U.S.", in U.S. Geological Survey, Proceedings of Workshop on Preparing for and Responding to a Damaging Earthquake in the Eastern U.S., Conference, XV, Open File Report 82-220, Reston, Virginia.

THIEL, C.C. [1984]: "Recovery following an earthquake: A prospective assessment for Arkansas following a Central U.S. earthquake", in U.S. Geological Survey, Open File Report 84-772.

THOOMAS, W. S. [1985]: “Impending crisis in earthquake insurance?” Risk Management, July 38-40.

TURCOTT, T. and ARIEH, E. [1986]: Catalog of Earthquakes In and Around Israel, prepared for the Israeli Electric Corporation, Preliminary Draft, September.

U.S. GEOLOGICAL SURVEY: "Proceedings of the Symposium on the New Madrid Seismic Zone", Department of the Interior, Open File Report 84-770, Reston, Virginia, 1984.

U.S. GEOLOGICAL SURVEY: "A Workshop on Geological Hazards on Puerto Rico, San Juan, April 84", Department of the Interior, Open File Report 84-761, Reston,Virginia, 1984.

WIGGINS, J.H. [1981]: "Earthquake hazard and risk mitigation”, J.H. Wiggins company, Redondo Beach, Ca. 


\section{Appendix 1: Modified Mercalli Scale (1956)}

\section{(From: Munich Re: World Map of Natural Hazards)}

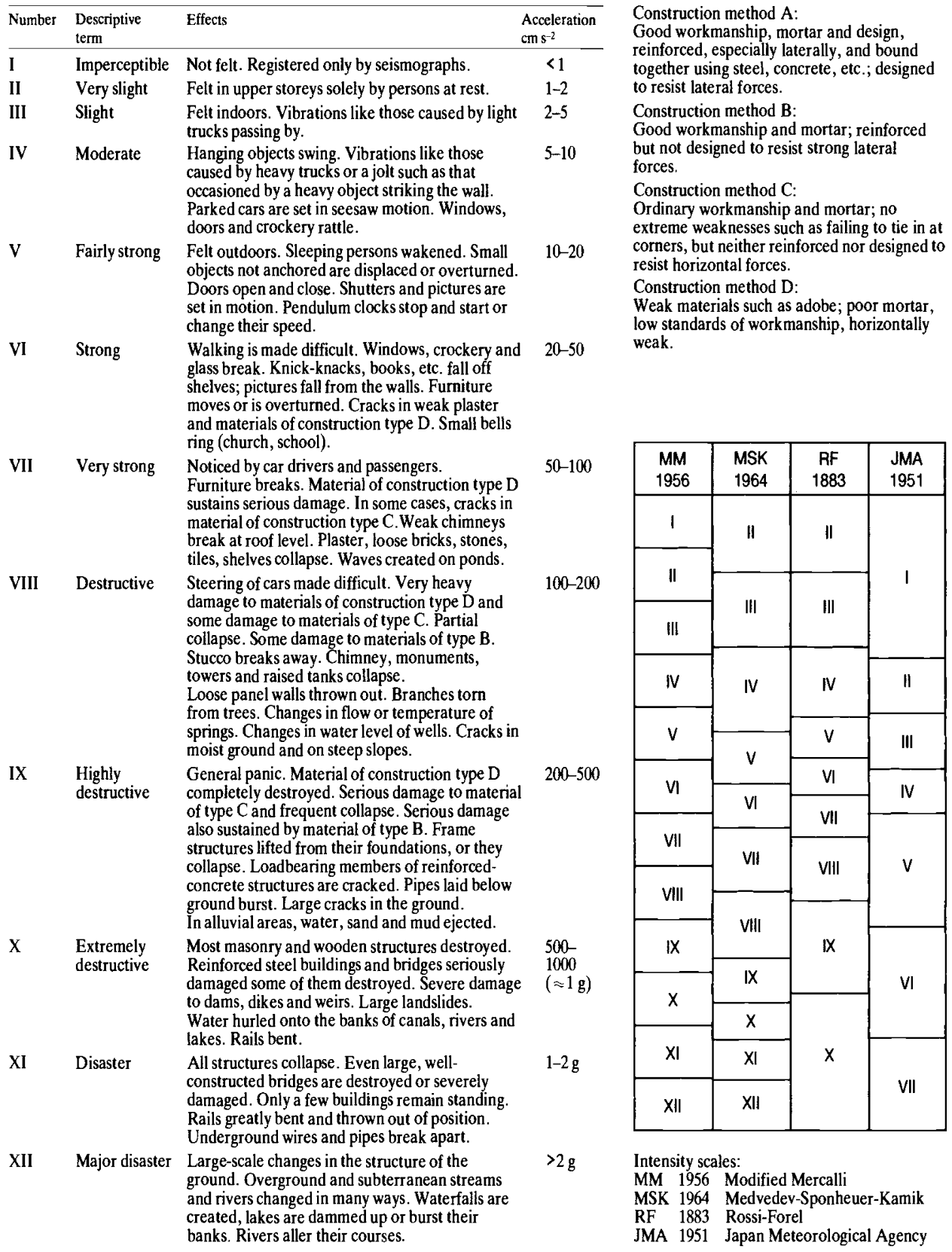

